\title{
Recombinant tissue plasminogen activator in cases with fibrin formation after cataract surgery: a prospective randomised multicentre study
}

\begin{abstract}
A Heiligenhaus, B Steinmetz, R Lapuente, P Krallmann, C Althaus, W K Steinkamp, B Dick
\end{abstract}

Conclusions-Lysis of postcataract fibrin formation is accelerated and increased by a single intracameral injection of $10 \mu \mathrm{g}$ tPA in addition to standard antiinflammatory treatment. The findings suggest that the tPA injection reduces posterior capsule fibrosis, which still has to be addressed in larger study populations and with a long term follow up. (Br f Ophthalmol 1998;82:810-815)

The incidence and degree of inflammation as a consequence of cataract surgery have decreased in recent years because of the surgical techniques that have evolved and improved intraocular lenses. ${ }^{1}$ Postoperative alteration of the blood-aqueous barrier, however, is inevitable. But this is usually easily managed with topical anti-inflammatory medication within several days. While fibrinous uveitis occurs in less than $3 \%$ of the cases after normal cataract extraction and intraocular lens implantation, ${ }^{2}$ fibrin exudation more frequently appears in children, in cases where there have been extensive surgical iris procedures, or in patients with diabetes or uveitis. ${ }^{3-6}$ This insoluble fibrin may eventually lead to synechiae, loss of pupillary function, membrane formation on the intraocular lens, IOL dislocation, or secondary glaucoma. Posterior capsule opacification, found in $15 \%-50 \%$ of the patients after cataract extraction, may also result from

Frankfurt,

Department of

Ophthalmology,

Germany

W K Steinkamp

Mühldorf, Germany B Steinmetz

University of Mainz, Department of Ophthalmology, Germany

B Dick

Hospital del Mar, Department of Ophthalmology, Barcelona, Spain R Lapuente

Correspondence to: Dr Heiligenhaus, University of Essen, Department of Ophthalmology,

Universitatsklinikum Essen, Hufelandstrasse 55, 45122 Essen, Germany.

\section{Clot formation}

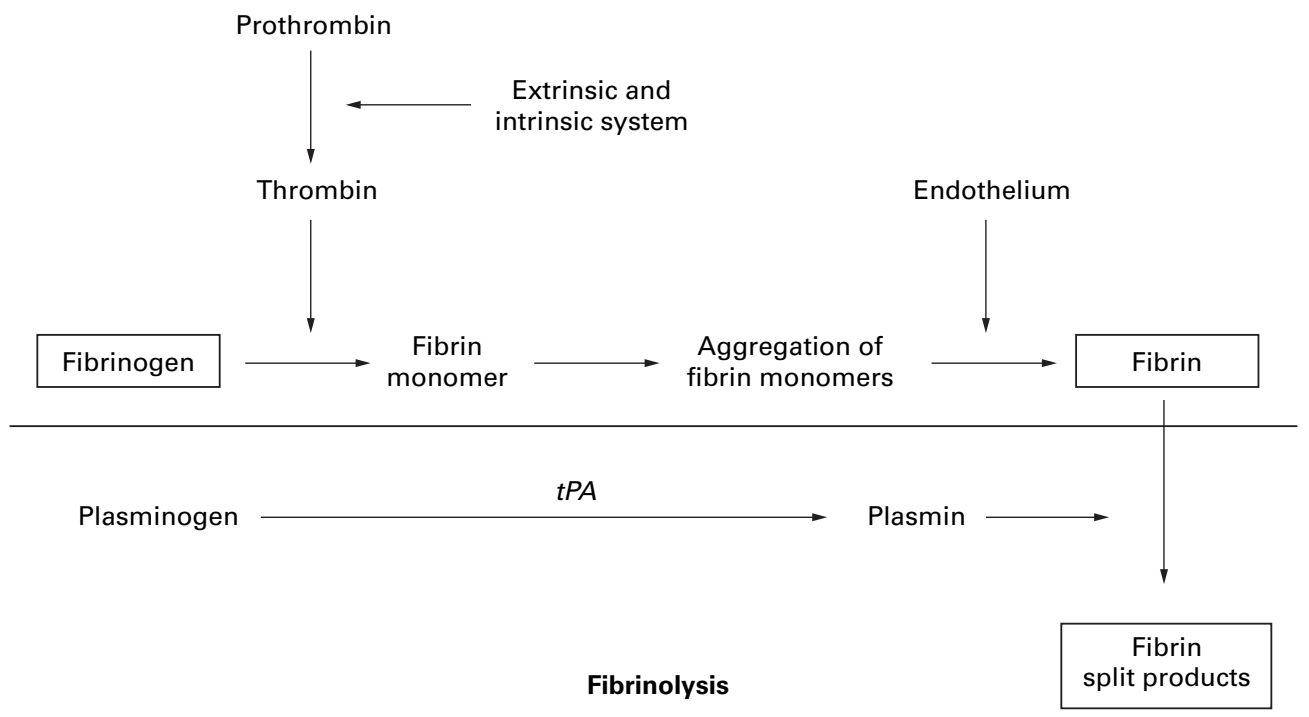

Figure 1 Diagram showing the action of tissue plasminogen activator (tPA). 
Table 1 Randomised prospective multicentre study on tPA in cases with fibrin formation after cataract surgery: inclusion and exclusion criteria

Inclusion criteria:

Intracameral fibrin membranes or clots after ECCE or phacoemulsification with PC-IOL Age: $18-90$ years

Able to participate for the entire follow up period

Exclusion criteria:

Known hypersensitivity to active ingredients or excipients of the study medication

Uncertain compliance

Known coagulopathy

Systemic thrombocyte aggregation inhibitors or coagulation inhibitors

Intraoperative posterior capsule rupture

Table 2 Randomised prospective multicentre study on tPA in cases with fibrin formation after cataract surgery: factors inducing fibrin exudation

\begin{tabular}{lc}
\hline Factors & No of patients \\
\hline Iris surgical manoeuvres & 11 \\
Rubeosis iridis & 3 \\
Uveitis & 8 \\
Diabetes mellitus & 21 \\
Rheumatic disease & 5 \\
Pseudoexfoliation syndrome & 3 \\
\hline
\end{tabular}

postoperative fibrinous reaction. ${ }^{1}$ Introduction of a potent fibrinolytic substance for the treatment of postsurgical fibrin formation therefore seems reasonable.

Recombinant tissue plasminogen activator (tPA) is a highly potent fibrinolytic protein. ${ }^{7-9}$ Its fibrinolytic activity is clot specific, which significantly decreases the risk of haemorrhages (Fig 1). Intravenous therapy with tPA has proved to be efficacious in coronary thrombolysis in patients after myocardial infarction. ${ }^{10}$ In several uncontrolled clinical trials intracameral tPA injections of $25 \mu \mathrm{g}$ or less have been shown to lyse postcataract intracameral fibrin membranes. ${ }^{11-14}$

This prospective study was undertaken to investigate the efficacy of anterior chamber injections of $10 \mu \mathrm{g} \mathrm{tPA}$ for resolution of severe fibrin formation following extracapsular cataract extraction (ECCE) or phacoemulsification with posterior chamber intraocular lens implantation (PC-IOL) in order to determine its effects on secondary complications such as synechiae or posterior capsule opacification and its tolerability.

Subjects and methods

Patients developing fibrin 2-8 days (mean 2.4 (SEM 1.2)) after ECCE or phacoemulsification with PC-IOL between October 1993 and May 1994 were included in this study. ECCE or phacoemulsification techniques were per-

Table 3 Randomised prospective multicentre study on tPA in cases with fibrin formation after cataract surgery: standardised variables studied before treatment and after days 1,2 , 14 , and 90

Visual acuity

Applanation tonometry

Lid (any changes)

Bulbar conjunctiva (chemosis, conjunctival or ciliary injection)

Tarsal conjunctiva (papillary or follicular hypertrophies, calcifications, scars)

Surgical wound (leakage, haemorrhage, dehiscence, chemosis, injection, secretion)

Cornea (transparency, epithelial oedema or defects, Descemet folds, guttae, endothelial pigment or cells)

Anterior chamber (depth, tyndall, fibrin, lens protein, cells, pigment, erythrocytes, hyphaema)

Iris (hyperaemia, stromal abnormalities, pupillary shape and diameter, anterior or posterior synechiae)

IOL (position, pigment cells, other cells, fibrin, membranes, synechiae)

Posterior capsule (cortical remnants, central opacification, regenerative secondary cataract) Medication (any, with dosages) formed. Dexamethasone, $4 \mathrm{mg}$, was injected subconjunctivally at the end of the surgery. The inclusion and exclusion criteria for this study are listed in Table 1. A detailed review of systems and eye examinations was performed when the patients were recruited to this study, which was carried out in accordance with the Declaration of Helsinki concerning medical research in humans. Patients were included in this study after informed consent was obtained.

The study was designed as an randomised prospective multicentre study. The postoperative treatment consisted of corticosteroids and antibiotic eye drops (four times daily, each) and ointment at bedtime, and of non-steroidal anti-inflammatory eye drops (four times daily). Patients with severe postsurgical fibrinous membranes or clots (Table 2) were assigned to one of the two study groups according to a randomisation schedule provided to each centre in advance. The frequency and dosage of topical steroids were adjusted as required in each case, and cycloplegics were added. While the standard treatment group continued with the anti-inflammatory regimen, the second group received in addition a single intraocular injection of $10 \mu \mathrm{g}$ tPA. Recombinant tissue plasminogen activator was supplied by Basotherm $\mathrm{GmbH}$, Biberach, Germany. Under sterile conditions, lyophilised tPA was dissolved in distilled water and buffer substance; $10 \mu \mathrm{l}$ of the solution containing $10 \mu \mathrm{g}$ tPA were injected into the anterior chamber under an operation microscope.

On days 1, 2, 14, and 90 after randomisation, applanation tonometry, visual acuity tests, and slit lamp examinations were performed. The eyelids, the conjunctiva, the wound area, cornea, anterior chamber, iris, IOL, and posterior capsule were evaluated in masked fashion. The findings were graded on scales and were documented in detailed standardised protocols (Table 3). The presence of intraocular fibrin was graded as slight (several fibrin strands), moderate (compact fibrin aggregates), or severe (fibrin membranes or clots).

The primary efficacy variable was the rate of fibrinolysis in the anterior chamber, on the IOL surface, or on the other intracameral structures. The secondary efficacy variables were the development of synechiae, regenerative secondary cataract, and central posterior capsule fibrosis. Any adverse events were reported, including patient complaints, physical signs, and diseases that occurred or worsened during the study period.

The statistical evaluation of the primary variable was performed by means of a $\chi^{2}$ test. The statistical analysis of the secondary variables was done with Student's $t$ test and the Mann-Whitney $U$ test; the frequencies were evaluated by means of a $\chi^{2}$ test. No interim analysis was performed.

\section{Results}

Eighty six patients were enrolled in this study. These were approximately $2 \%$ out of the total number of cataract surgeries performed in the 
Table 4 Randomised prospective multicentre study on tPA in cases with fibrin formation after cataract surgery

\begin{tabular}{llll}
\hline (A) Presence of fibrin & & & \\
\hline & & & \\
Days after treatment & $t P A(n=44)$ & $\begin{array}{l}\text { Standard therapy } \\
(n=41)\end{array}$ & $\begin{array}{l}\text { Statistical } \\
\text { significance }\end{array}$ \\
\hline Any intraocular fibrin: & $100 \%$ & & $\mathrm{~ns}$ \\
Before therapy & $59.1 \%$ & $100 \%$ & $\mathrm{p}=0.001$ \\
1 & $59 \%$ & $95.1 \%$ & $\mathrm{p}=0.001$ \\
2 & $11.4 \%$ & $90.3 \%$ & $\mathrm{p}=0.039$ \\
14 & $0 \%$ & $29.3 \%$ & $\mathrm{~ns}$ \\
90 & & $2.4 \%$ & $\mathrm{~ns}$ \\
Anterior chamber fibrin: & $84.1 \%$ & $85.4 \%$ & $\mathrm{p}=0.0009$ \\
Before therapy & $45.5 \%$ & $80.5 \%$ & $\mathrm{p}=0.001$ \\
1 & $43.2 \%$ & $78.0 \%$ & $\mathrm{~ns}$ \\
2 & $2.3 \%$ & $9.8 \%$ & $\mathrm{~ns}$ \\
14 & $0 \%$ & $0 \%$ & $\mathrm{~ns}$ \\
90 & & & $\mathrm{nd}$ \\
OOL surface fibrin: & $97.7 \%$ & $92.7 \%$ & $\mathrm{p}=0.000067$ \\
Before therapy & $\mathrm{nd}$ & $\mathrm{nd}$ & $\mathrm{p}=0.05$ \\
1 & $47.7 \%$ & $80.5 \%$ & $\mathrm{~ns}$ \\
2 & $9.1 \%$ & $24.4 \%$ & \\
14 & $0 \%$ & $2.4 \%$ & \\
90 & & &
\end{tabular}

(B) Rate of intraocular fibrin 1 and 14 days after treatment

\begin{tabular}{llllllll}
\hline \multirow{2}{*}{$\begin{array}{l}\text { Days after } \\
\text { treatment }\end{array}$} & \multicolumn{2}{l}{$t P A(n=44)$} & & & \multicolumn{3}{c}{ Standard therapy $(n=41)$} \\
\cline { 2 - 3 } & 1 & 14 & 90 & & 1 & 14 & 90 \\
\hline None & $40.9 \%$ & $93.2 \%$ & $100 \%$ & & $4.9 \%$ & $75.6 \%$ & $97.6 \%$ \\
Mild & $31.8 \%$ & $6.8 \%$ & $0 \%$ & & $46.3 \%$ & $24.4 \%$ & $2.4 \%$ \\
Moderate & $25 \%$ & $0 \%$ & $0 \%$ & & $39 \%$ & $0 \%$ & $0 \%$ \\
Severe & $2.3 \%$ & $0 \%$ & $0 \%$ & & $9.8 \%$ & $0 \%$ & $0 \%$ \\
\hline
\end{tabular}

U test: day 1: p=0.00069; day $14: \mathrm{p}=0.025$; day 90 : ns.

nd=not documented, ns=no significant difference.

Table 5 Randomised prospective multicentre study on tPA in cases with fibrin formation after cataract surgery: prerandomisation incidence of synechiae and rate of synechiolysis

\begin{tabular}{lll}
\hline & $t P A$ & $\begin{array}{l}\text { Standard } \\
\text { therapy }\end{array}$ \\
\hline $\begin{array}{l}\text { Patients with synechiae before tPA } \\
\text { Rate of synechiolysis }\end{array}$ & $15 / 44$ & $13 / 41$ \\
$\begin{array}{l}\text { Days after treatment: } \\
2\end{array}$ & $73.3 \%$ & $30.8 \%$ \\
14 & $73.3 \%$ & $46.2 \%$ \\
90 & $80 \%$ & $46.2 \%$ \\
\hline
\end{tabular}

Table 6 Randomised prospective multicentre study on tPA in cases with fibrin formation after cataract surgery

(A) Incidence of posterior capsule opacification and regenerative secondary cataract

\begin{tabular}{llll}
\hline Days after treatment & $t P A(n=44)$ & $\begin{array}{l}\text { Standard therapy } \\
(n=41)\end{array}$ & Statistical significance \\
\hline $\begin{array}{l}\text { Posterior capsule opacification } \\
1\end{array}$ & $15 \%$ & $22.1 \%$ & $\mathrm{p}=0.36$ \\
2 & $13.6 \%$ & $24.6 \%$ & $\mathrm{p}=0.21$ \\
14 & $34.1 \%$ & $51.2 \%$ & $\mathrm{p}=0.06$ \\
90 & $53.5 \%$ & $75.7 \%$ & $\mathrm{p}=0.027$ \\
Posterior capsule regenerative secondary cataract & & \\
1 & $4.9 \%$ & $2.5 \%$ & $\mathrm{p}=0.57$ \\
2 & $4.8 \%$ & $0 \%$ & $\mathrm{p}=0.17$ \\
14 & $4.8 \%$ & $0 \%$ & $\mathrm{p}=0.17$ \\
90 & $10 \%$ & $20.6 \%$ & $\mathrm{p}=0.2$ \\
\hline
\end{tabular}

(B) Posterior capsule opacification 1 and 90 days after treatment

\begin{tabular}{llllll}
\hline \multirow{2}{*}{ Days after treatment } & \multicolumn{2}{l}{$t P A$} & & \multicolumn{2}{l}{ Standard therapy } \\
\cline { 2 - 3 } \cline { 5 - 6 } & 1 & 90 & & 1 & 90 \\
\hline None & $85 \%$ & $46.5 \%$ & & $76.9 \%$ & $24.3 \%$ \\
Mild & $10 \%$ & $30.2 \%$ & & $12.8 \%$ & $32.4 \%$ \\
Moderate & $2.5 \%$ & $20.9 \%$ & & $10.3 \%$ & $40.5 \%$ \\
Severe & $2.5 \%$ & $2.3 \%$ & & $0 \%$ & $2.7 \%$ \\
\hline
\end{tabular}

U test: day $1: \mathrm{p}=0.36$; day $90: \mathrm{p}=0.027$; standard treatment group: $\mathrm{n}=41$; tPA group: $\mathrm{n}=44$. six centres during the study period. Forty four patients were in the tPA treated group and 41 patients belonged to the standard treatment group. One patient from the tPA group was excluded from the efficacy assessment, because he suffered from aphakia. One tPA treated patient and two patients treated with the standard treatment missed their appointments after 3 months. Two patients in the standard treatment group left the study after the day 14 visit because of rapid development of capsule fibrosis. The "last observation carried forward method" was employed for these missing data. Forty seven patients were women, 39 were men. The mean age was 69.5 years (SEM 12.2) and 72.1 years (12.6) in the tPA and standard treatment groups, respectively. The epidemiological, preoperative ocular characteristics or surgical methods did not differ significantly between patients in the tPA and control group.

Two and 14 days after treatment, the incidence and rate of intraocular fibrin, both in the anterior chamber or on the IOL surface, were significantly lower in the tPA treated group than in the control group (Table 4). Fibrinolysis was significantly accelerated by the additional tPA injection. The amount of fibrin present in individuals treated with tPA was significantly less at all follow up visits (Table 4B). The frequency of posterior synechiae to the intraocular lenses was reduced by the tPA injection, but the difference between groups did not reach the level of statistical significance (Table 5). The incidence of posterior capsule fibrosis did not differ between the two study groups at days 1,2 , and 14 . The capsule fibrosis noted at the day 90 follow up visit in the tPA group was significantly less than in the patients treated with standard anti-inflammatory drugs (Table 6). In contrast, regenerative secondary cataract formation was similar in both study groups. The rates of capsule fibrosis or regenerative cataract formation did not differ between the six centres or the various surgeons involved in the study. The final visual acuities at day 90 after treatment were significantly better in the tPA treated group than in the cases in the control group $(p<0.01$; Table 7$)$. The preoperative and postoperative antiinflammatory regimens did not significantly differ between both groups.

All patients $(n=86)$ were included in the safety analysis. Adverse events were found in three patients in each group, which could not be attributed to the ocular treatment. One patient in the tPA group suffered from fever and biliary colic, which required surgery. In a second case, chronic iritis recurred, and another patient suffered from varicosis of his leg. Two patients in the control group developed rapid capsule fibrosis, and posterior synechiae in the optical axis were seen in another. Hyphaema has not been observed in a single case followed up in this study. Corneal complications, wound healing problems, or disturbances in the intraocular pressure were not found in any of the patients. All of the other study variables listed in Table 3 did not differ 
Table 7 Randomised prospective multicentre study on tPA in cases with fibrin formation after cataract surgery: visual acuity and complications

\begin{tabular}{|c|c|c|c|c|c|}
\hline \multirow[b]{2}{*}{ tPA treated group } & \multirow[b]{2}{*}{ Before treatment } & \multicolumn{4}{|c|}{ After treatment } \\
\hline & & Day 1 & Day 2 & Day 14 & Day 90 \\
\hline Hyphaema & - & - & - & - & - \\
\hline Corneal complications & - & - & - & - & - \\
\hline Wound healing complications & - & - & - & - & - \\
\hline $\mathrm{IOP}(\mathrm{mm} \mathrm{Hg})$ & $14.7(5.5)$ & $14.0(4.2)$ & $14.5(4.3)$ & $15.1(3.8)$ & $15.1(3.6)$ \\
\hline \multirow[t]{2}{*}{ Vision } & $0.22(0.23)$ & nd & nd & $0.48(0.31)$ & $0.56(0.3)$ \\
\hline & & \multicolumn{4}{|c|}{ After treatment } \\
\hline Standard treatment group & Before treatment & Day 1 & Day 2 & Day 14 & Day 90 \\
\hline Hyphaema & - & - & - & - & - \\
\hline Corneal complications & - & - & - & - & - \\
\hline Wound healing complicationss & - & - & - & - & - \\
\hline $\mathrm{IOP}(\mathrm{mm} \mathrm{Hg})$ & $14.7(5.4)$ & $14.3(4.5)$ & $15.2(5.0)$ & $14.3(3.2)$ & $14.9(3.0)$ \\
\hline Vision & $0.29(0.26)$ & nd & nd & $0.44(0.33)$ & $0.51(0.33)$ \\
\hline
\end{tabular}

Standard treatment group: $\mathrm{n}=41 ;$ tPA group: $\mathrm{n}=44$.

nd=not documented.

significantly between the study groups at any of the follow up visits.

\section{Discussion}

The high success rate of modern cataract surgery may be significantly impaired by postoperative intraocular fibrinous reactions and fibrin related complications. Since fibrin and fibrinogen degradation products promote chemotaxis and activation of intraocular inflammatory components ${ }^{15}$ or cellular transformation into fibrocytic cells, ${ }^{16}$ stabilisation of the blood-aqueous barrier function by antiinflammatory drugs is the mainstay of current treatment. However, active fibrinolysis may be a more potent therapeutic option.

This is the first prospective randomised study on the use of tPA in patients developing severe intracameral fibrinous exudation after cataract surgery. The efficacy of $10 \mu \mathrm{g}$ tPA administered by anterior chamber injection was assessed with regard to fibrinolysis, lysis of synechiae to the IOL, and development of posterior capsule fibrosis in comparison with a standard topical anti-inflammatory medical regimen. The results indicate that lysis of intracameral fibrin can be improved by the tPA injection. In tPA treated patients, fibrinolysis was completed within the first day in $40.9 \%$ of the cases, and in $93.2 \%$ of these patients within 2 weeks. In contrast, $95.1 \%$ of the patients in the control group still had significant intracameral fibrin deposition after the first day, and $24.4 \%$ even after 2 weeks. Our observation that tPA is highly effective for the acceleration of fibrinolysis is in accord with several previous experimental and uncontrolled clinical investigations. ${ }^{11} 1314$ 17-21

In our study, complete lysis of intracameral fibrin depositions was achieved with the use of only $10 \mu \mathrm{g}$ tPA. Continued production or reaccumulation of fibrin after injecting the tPA has not been seen in any of our patients, which might be attributed to the continued treatment with anti-inflammatory medications. Especially with tPA dosages below $10 \mu \mathrm{g}$, repeated tPA injections have previously been necessary to achieve complete fibrinolysis. ${ }^{2022} 23$ The rapid fibrinolysis seen in this and previous studies $^{11} 1421$ and the markedly diminished effi- cacy of tPA in cases treated several weeks after fibrin deposition ${ }^{24}$ are evidence in favour of prompt treatment with tPA in cases with severe postcataract fibrinous responses.

Regarding the lysis of visible synechiae, tPA injection was more effective than the standard anti-inflammatory treatment. The $80 \%$ success rate of synechiolysis in the tPA treated group noted after 3 months compared favourably with the $46.2 \%$ in the control group. The incidence of pupillary dysfunction, another supportive marker for fibrin deposition at the pupil and for posterior synechiae, increased in the standard treatment group, while it decreased in the tPA group (data not shown).

The study design presented here is closely reflecting the clinical setting that fibrin formation occurs under the perioperative use of antiinflammatory medication. Although anterior chamber injections in postcataract patients already complicated by fibrin formation might induce additional inflammation and fibrin, this did not occur in this series. A randomised, double blind design including a control group injected with the vehicle alone is prohibited ethically for obvious reasons. However, it is highly likely that the difference between the tPA injected group and the non-injected group of patients found in the present study is attributed to the active ingredient. Although the topical corticosteroid treatment was not standardised, the dosages did not differ significantly between both study groups. Therefore, this did not introduce a bias to this study.

The most frequent complication after cataract surgery is posterior capsule fibrosis, which may occur in up to half of the patients. ${ }^{25}$ It is well known that secondary opacification of the posterior capsule is often caused by the proliferation of remnant or regenerated lens epithelial cells left in the capsular bag. ${ }^{26}$ There is, however, compelling evidence that proliferation, migration, and metaplasia of lens epithelial cells are related to postoperative disruption of the blood-aqueous barrier and are associated with exudation of fibrinogen and fibrin..$^{27-31}$ While the transparent fibrinous membranes may not obscure vision, the newly formed fibrous tissue may result in significant visual impairment. ${ }^{26}$ Soluble fibrinogen not 
visible with the slit lamp is converted to fibrin. This is followed by platelet activation and by the secretion of platelet derived growth factor, which has a strong mitogenic effect on fibroblasts. In a second step, cells produce the extracellular matrix components. Experimental studies by Fourman and Wiley ${ }^{33}$ have provided evidence that tPA is able to reduce levels of those extracellular matrix components which are implicated in capsule fibrosis. ${ }^{34}$ Therefore, tPA may be a drug candidate for diminishing secondary cataract formation.

The observations in this study suggest that tPA treatment may reduce posterior capsule fibrosis. The reduced frequency and severity of posterior capsule fibrosis seen in the tPA treated group reached the level of statistical significance at 3 months after treatment. Accordingly, the final vision in the tPA treated patients was significantly better, while the preoperative visual acuities were similar in both study groups. However, this important issue must be addressed in future in larger study populations and with long term follow up, since the development of secondary cataract formation is highly variable, ranging from weeks to years. More accurate measures to judge capsule fibrosis, such as automated densitometry or contrast sensitivity, should be added to these studies. Based on our data, no conclusions can be arrived at as to whether or not treatment with intraocular tPA decreases the need for Nd:YAG laser capsulotomy. Avoiding Nd:YAG capsulotomy and its serious complications ${ }^{35}$ would undoubtedly be attractive.

The consensus based on previous work and ours is that the injection of $10 \mu \mathrm{g} \mathrm{tPA}$ into the anterior chamber is generally well tolerated. No corneal complications were detected on slit lamp examination in our patients treated with tPA. In recent studies, no evidence of corneal endothelial damage has resulted from the intracameral use of tPA, even at high dosages. ${ }^{1136}$ However, band keratopathy rarely occurred following tPA injection. ${ }^{37}$ The tPA treatment in this study has not been complicated by uveitis or disturbances in the intraocular pressure. In recent experimental studies, no toxic side effects were found after injecting 5-10 $\mu \mathrm{g}$ of tPA into the anterior chamber. ${ }^{38}$ Retinal toxicity in lensectomised and vitrectomised rabbits only occurred with intravitreal tPA dosages above $50 \mu \mathrm{g} .{ }^{39}$ No such side effects have been noted in our clinical study.

Several groups have reported severe bleeding complications after injecting tPA into the eye. ${ }^{20-22}$ This was especially true in cases with neovascularisation, iris surgical manoeuvres, cataract extraction combined with trabeculectomy or vitrectomy, uveitis, diabetes, after trauma, and when tPA was given immediately after surgery. ${ }^{20} 20$ In previous uncontrolled studies on the use of $25 \mu \mathrm{g} \mathrm{tPA}$ in patients with postcataract fibrinous membranes, hyphaema developed in $7.6 \%-10.5 \%$ of the cases. ${ }^{11}{ }^{13}$ Our data indicate that the use of intracameral injections of $10 \mu \mathrm{g} \mathrm{tPA}$ following the first postoperative day appears to be safe as far as the bleeding is concerned, and this is supported by previous uncontrolled reports. ${ }^{14}{ }^{18}$ The bleeding complication, however, is evidence of the need to limit the dosage of tPA and to restrict its usage.

The potential advantage of epibulbar tPA delivery to the eye is that it diminishes the potential side effects. However, topical or subconjunctival tPA applications produced low and variable intracameral drug levels ${ }^{41}{ }^{42}$ implying that this route of administration in the currently available formulations is unsuitable for this clinical purpose.

The authors have no commercial interest in the material used in the study.

1 Apple DJ, Solomon KD, Tetz MR, et al. Posterior capsule opacification. Surv Ophthalmol 1992;37:73-116.

2 Sterling S, Wood T. Effect of intraocular lens convexity on posterior capsule opacification. I Cataract Refract Surg 1986;12:655-7.

3 Little HL Alterations in blood elements in the pathogenesis of diabetic retinopathy. Ophthalmology 1981;88:647-54.

4 Sebestyen JG. Fibrinoid syndrome. A severe complication of vitrectomy surgery in diabetes. Ann Ophthalmol 1982;14: 853-8.

5 Miyake K, Asakura M, Kobayashi H. Effect of intraocular lens fixation on the blood-aqueous barrier. Am $\mathcal{F}$ Ophthalmol 1984;98:451-5.

6 Goodman DF, Stark WJ, Gottsch JD. Complications of cataract extraction with intraocular lens implantation. Ophthalmic Surg 1989;20:132-40.

7 Thorsen S, Glas-Greenwalt P, Astrup T. Differences in the binding to fibrin of urokinase and tissue plasminogen activator. Thrombos Diathes Haemorrh 1972;28:65-74.

8 Collen D, Lijnen HR. Tissue type plasminogen activator. Mechanism of action and thrombolytic properties. Haemostasis 1986;16(suppl 3):25-32.

9 Pennica D, Holmes WE, Kohr WJ, et al. Cloning and expression of human tissue-type plasminogen activator expression of human tissue-type plasmi
cDNA in E coli. Nature 1983;301:214-21.

10 Werf van de F, Bergmann SE, Fox KAA, et al. Coronary thrombolysis with intravenously administered human tissue type plasminogen activator produced by recombinant DNA technology. Circulation 1984;96:605-10.

11 Moon J, Chung S, Myong Y, et al. Treatment of postcataract fibrinous membranes with tissue plasminogen activator. Ophthalmology 1992;99:1256-9.

12 Körner F, Böhnke M. Clinical use of recombinant plasminogen activator for intraocular fibrinolysis. Ger $\mathcal{F}$ Ophthalmol 1992;1:354-60.

13 Wedrich A, Menapace R, Muehlbauer-Ries F. The use of recombinant tissue plasminogen activator for intracameral fibrinolysis follwing cataract surgery. Int Ophthalmol 1995; 18:277-80.

14 Heiligenhaus A, Schilling $\mathrm{H}$, Schilling $M$, et al. Behandlung mit Gewebsplasminogenaktivator (tPA) bei Risikopatienten mit Fibrinreaktionen nach Kataraktoperationen. Ophthalmologe 1996;93:49-53.

15 Rowland FN, Donavan MJ, Gillies C, et al. Fibrin: mediator of in vivo and in vitro injury and inflammation. Curr Eye Res 1985;4:537-53.

16 Vidaurri-Leal JS, Glaser BM. Effect of fibrin on morphologic characteristics of retinal pigment epithelial cells. Arch Ophthalmol 1984;102:1376-9.

17 Snyder RW, Lambrou FH, Williams GA. Intraocular fibrinolysis with recombinant human tissue plasminogen activator. Experimental treatment in a rabbit model. Arch Ophthalmol 1987;105:1277-80.

18 Johnson RN, Olson K, Hernandez E Tissue plasminogen activator treatment of postoperative intraocular fibrin. Ophthalmology 1988;95:592-6.

19 Williams GA, Lambrou FH, Jaffe GA, et al. Treatment of postvitrectomy fibrin formation with intraocular tissue plasminogen activator. Arch Ophthalmol 1988;106:1055-8.

20 Dabbs CK, Aaberg TM, Aguilar HE, et al. Complications of tissue plasminogen activator therapy after vitrectomy for tissue plasminogen activator therapy after vite

21 Jaffe GJ, Abrams GW, Williams GA, et al. Tissue plasminogen activator for postvitrectomy fibrin formation. Ophthalmology 1990;97:184-9.

22 Williams DF, Bennett SR, Abrams GW, et al. Low-dose intraocular tissue plasminogen activator for treatment of postvitrectomy fibrin formation. Am f Ophthalmol 1990; 109:606-7.

23 Boldt HC, Abrams GW, Murray TG, et al. The lowest effective dose of tissue plasminogen activator for fibrinolysis of postvitrectomy fibrin. Retina 1992;12:75-9.

24 Folk JC, Hershey JM, Rivers MB. Lack of effectiveness of tissue plasminogen activator 20 or more days after vitrectomy. Arch Ophthalmol 1991;109:614.

25 Wilhelmus K, Emery J. Posterior capsule opacification following phacoemulsification. Ophthalmic Surg 1980;11: 264-7.

26 McDonnell P, Zarbin M, Green W. Posterior capsule opacification in pseudophakic eyes. Ophthalmology 1983;90: 1548-53. 
27 Fagerholm PP, Philipson BT. Experimental traumatic cataract. II. A transmission electron microscopy and extracellular tracer study. Invest Ophthalmol Vis Sci 1979;18:1160-71.

28 Fagerholm $\mathrm{P}$. The response of the lens to trauma. Trans Ophthalmol Soc UK 1982;102:369-74.

29 Miyake K. Blood-retinal barrier in long-standing aphakic eyes after extra- and intracapsular lens extractions. Graefes Arch Clin Exp Ophthalmol 1985;222:232-3.

30 Nishi O. Fibrinous membrane on the posterior chamber lens during the early postoperative period. 7 Cataract Refract Surg 1988;14:73-7.

31 Krupsky S, Zahlish M, Oliver M, et al. Anterior segment complications in diabetic patients following extracapsular cataract extraction and posterior chamber intraocular lens implantation. Ophthalmic Surg 1991;22:526-30.

32 Apple DJ, Mamalis N, Loftfield K, et al. Complications of intraocular lenses. A historical and histopathological review. Surv Ophthalmol 1984;29:1-54.

33 Fourman S, Wiley S. Tissue plasminogen activator modifies healing of glaucoma filtering surgery in rabbits. Ophthalmic hurg 1991;22:718-23.

34 Ishibashi T, Hatae T, Inomata H. Collagen types in human posterior capsule opacification. F Cataract Refract Surg 1994;20:643-6.

35 Steinert RF, Puliafito CA, Kumar SR, et al. Cystoid macular edema, retinal detachment and glaucoma after Nd:YAG laser posterior capsulotomy. Am f Ophthalmol 1991;112: 373-80.

36 McDermott ML, Edelhauser HF, Hyndiuk RA, et al. Tissue plasminogen activator and the corneal endothelium. Am F Ophthalmol 1989;108:91-2

37 Althaus C, Schelle C, Sundmacher R. Akute bandförmige Keratopathie nach intraokularer Fibrinolyse mit rekombinantem Tissue-Plasminogen-Aktivator. Klin Monatsbl Augenheilkd 1996;209:43-6.

38 Vogelberg K, Böhnke M, Koerner F, et al. Tolerability of a single injection of biological active rt-PA in the rabbit eye. Invest Ophthalmol Vis Sci 1993;34(suppl):1195.

39 Irvine WD, Johnson MW, Hernandez E, et al. Retinal toxicity of human tissue plasminogen activator in vitrectomized rabbit eyes. Arch Ophthalmol 1991:109:718-22.

40 Lundy DC, Sidoti P, Winardo T, et al. Intracameral tissue plasminogen activator after glaucoma surgery. Indications, effectiveness, and complications. Ophthalmology 1996;103: $274-82$.

41 Lim JI, Fiscella R, Tessler H, et al. Intraocular penetration of topical tissue plasminogen activator. Arch Ophthalmol 1991;109:714-7.

42 Lim JI, Maguire AM, John G, et al. Intraocular tissue plasminogen activator concentrations after subconjunctival delivery. Ophthalmology 1993;100:373-6. 